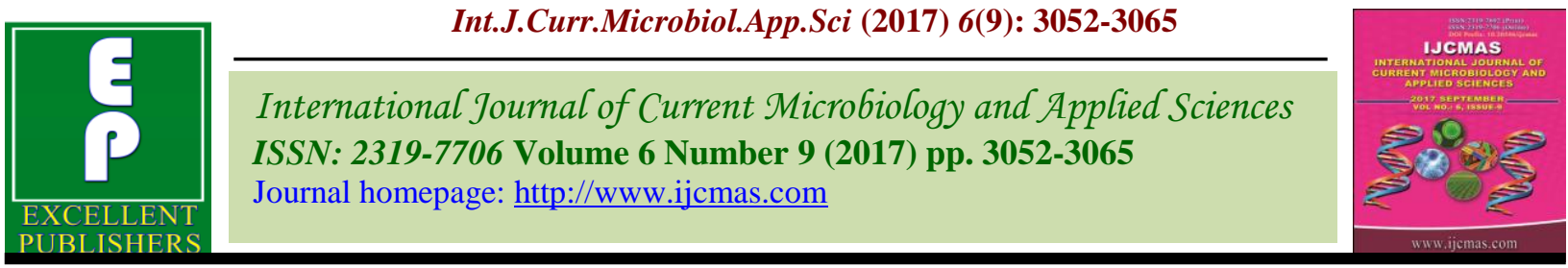

Case Study

https://doi.org/10.20546/ijcmas.2017.609.376

\title{
Estimation of Pan Evaporation Using Artificial Neural Networks - A Case Study
}

\author{
S. Sajeena*, V. Amrutha Gayathry and V.K. Sharmina
}

ICAR Krishi Vigyan Kendra Malappuram, Kerala Agricultural University, Tavanur, Malappuram 679573, Kerala, India

*Corresponding author

\section{A B S T R A C T}

The process of evaporation is influenced by a number of factors, the most common and important meteorological parameters affecting evaporation are solar radiation, temperature, relative humidity, wind speed and atmospheric pressure. There are number of

Keywords

Evaporation, Artificial Neural Network, Wind speed, Dry bulb temperature, Wet bulb temperature and MATLAB.

Article Info

Accepted:

28 August 2017

Available Online:

10 September 2017 models for the estimation of evaporation developed by investigators in different fields of study. The interrelated factors are incorporated into various formulae for estimating evaporation. Due to complex interactions between the components of the land-plantatmospheric systems the reliable estimation of evaporation are extremely difficult. The objective of this study was to develop an evaporation model for the K.C.A.E.T. campus, Tavanur using Artificial Neural Network (ANN) technique and MATLAB software. Monthly observations of meteorological parameters during the period February 2003 to January 2009 collected were used for the model development. The entire data is divided into three categories as pre-monsoon observations, monsoon observations and post monsoon observations. So each category consists of 24 observations of each parameter. From this study, it could be seen that the wind speed had greater influence on the evaporation rate during all seasons. Out of the five strategies considered for the study, the strategy with wind speed, dry bulb temperature and wet bulb temperature (strategy M- 3) was found to be the accurate combination for the estimation of evaporation during all the seasons with comparatively least MSE and high $\mathrm{R}^{2}$ value when compared with other strategies. Hence, it can be concluded that the combination of wind speed, dry bulb temperature and wet bulb temperature has great influence on the evaporation during all seasons.

\section{Introduction}

Evaporation is a major component of hydrologic cycle. It plays an important role in water resources development and management in arid and semi-arid climatic regions. Evaporation takes place whenever there is a vapour pressure gradient between a water surface and the overlying atmosphere with an energy source. There are number of models for the estimation of evaporation developed by investigators in different fields of study. Over the past two decades, 'Artificial Neural Networks (ANNs)' have been increasingly employed in modelling of hydrological process because of their ability to model non-linear systems. According to Dr. Robert Hecht-Nielsen (1989), a neural network can be defined as; "a computing system made up of a number of simple, highly 
interconnected processing elements, which information by their dynamic state response to external input". An Artificial Neural Network (ANN) is a method of computation and information processes that mimics the process of biological neurons found in the human brain. ANN's have been successfully applied across an extraordinary range of problem domains in areas as diverse as Finance, Medicine, Physics, Engineering, Geology and Hydrology (ASCE task committee on application of Artificial Neural Networks in hydrology 2000).

The ANN modelling and evaluation, use the software, MATLAB (ver. 7.6.0.324 (R2008a)) as the source code program. MATLAB is a high-level language and interactive environment for numerical computation, visualization and programming; it is used extensively by control engineers for analysis of design. MATLAB can be used to analyze data, develop algorithms and to create models and applications. An application of MATLAB includes signal processing, control systems, test and measurement, computational finance and computational biology. Objectives of the present study are to analyze the possibility of application of Artificial Neural Network in the field of hydrology and to develop, test and evaluate a daily pan evaporation model for KCAET campus using Artificial Neural Network (ANN).

\section{Materials and Methods}

The experiment was conducted in K.C.A.E.T. campus at Tavanur in Malappuram District which is situated at $10^{\circ} 51^{\prime} 23$ " North latitude and $75^{\circ}$ 59'13" East longitudes and lie adjoining to the Bharathappuzha River. The total geographical area of the region is about 40.25 ha with average annual rainfall of 2793 $\mathrm{mm}$. The climate is generally hot and humid. The average relative humidity of the area is $83 \%$. The maximum and minimum temperature ranges from 28.9 to $36.2^{\circ} \mathrm{C}$ and the $\mathrm{t} 17$ to $23.3^{\circ} \mathrm{C}$ respectively. The mean evaporation of the study area is $6 \mathrm{~mm} /$ day.

Data were taken from meteorological observatory of K.C.A.E.T campus. The parameters considered are; monthly observation of wind speed $(\mathrm{m} / \mathrm{s})$, dry bulb temperature $\left({ }^{\circ} \mathrm{C}\right)$, wet bulb temperature $\left({ }^{\circ} \mathrm{C}\right)$, maximum temperature $\left({ }^{\circ} \mathrm{C}\right)$, minimum temperature $\left({ }^{\circ} \mathrm{C}\right)$ and evaporation $(\mathrm{mm})$. For purpose of the study monthly observations from February 2003 to January 2009 is considered. The entire data is divided into three categories as pre-monsoon observations, monsoon observations and post monsoon observations. So each category consists of 24 observations of each parameter. The model development data set was further divided by randomly placing $70 \%$ of the observations in a training data set, $15 \%$ in a testing data set and the remaining $15 \%$ for validation of developed model. The training data set was used to develop the neural network models. The testing set was used to evaluate the accuracy of the ANN models during training in order to determine when to stop the training. The meteorological data is imported to the MATLAB workspace. The input is a 24 $\mathrm{x} n$ matrix, which includes 24 observations of $\mathrm{n}$ variables, where $\mathrm{n}$ is the number of inputs considered in the particular strategy.

Monthly observed Evaporation data corresponding to each season is selected as target. The target is a $24 \times 1$ matrix, which includes 24 observations of 1 variable. Number of hidden layer selected as 10 for the development of the neural network. The number of input will vary according to the strategy selected for developing the neural network. The number of hidden layer is considered as same for all the strategy. 16 samples were taken for training (about $70 \%$ of total sample) procedure. The networks trained to fit the input and output. These 
samples were presented to the network during the training and network was adjusted according to its error. The network will be trained with Levenberg-Marquardt backpropagation algorithm (trainlm). Training automatically stops when generalization stops improving, as indicated by an increase in the mean square error of the validation samples. Training multiple times will generate different results due to different initial conditions and sampling. 4 samples were taken $(15 \%)$ for the validation and these samples were used to measure network generalization, and to halt training when generalization stops improving. 4 samples were taken (15\%) for the testing of generated network and these samples have no effect on training and so provide an independent measure of network performance during and after training.

For the training of the created network, Levenberg-Marquardt (trainlm) network training function is used in this study. Levenberg-Marquardt (trainlm) is a network training function that updates weight and bias values according to Levenberg-Marquardt optimization. Trainlm is often the fastest backpropagation algorithm in the tool box. Mean Squared Error (MSE) is used for calculating the error which is obtained from the average squared difference between outputs and targets. Lower values are better. Zero means no error. MSE is a network performance function. It measures the network's performance according to the mean of squared errors. Regression is the process of fitting models to data. The process depends on the model. If a model is parametric, regression estimates the parameters from the data. If a model is linear in the parameters, estimation is based on methods from linear algebra that minimize the norm of a residual vector. If a model is nonlinear in the parameters, estimation is based on search methods from optimization that minimize the norm of a residual vector.

\section{Results and Discussion}

The meteorological parameters had been examined and a corresponding evaporation model was developed. The plot between the observed evaporation and estimated evaporation showed the linear relationship. The coefficient of regression $\left(\mathrm{R}^{2}\right)$ value was obtained from this plot, which defines the relation between the combination of the inputs selected for each strategy and the corresponding estimated evaporation. The variation between the observed and estimated evaporation data can be obtained as Mean Squared Error (MSE). The error can be represented graphically through a plot between the evaporation (y-axis) with time (months) in x-axis. This graph showed the accuracy of the field observation of the evaporation. The green line indicates the observed value from the meteorological observatory in the study area. The red line indicates the estimated value of the evaporation which was obtained through the ANN technique with the help of MATLAB.

\section{Pre-monsoon season}

The plot between observed and estimated evaporation of different strategies are shown in figure 1 and the $\mathrm{R}^{2}$ value obtained from this figure indicated the correlation between estimated or observed evaporation.

Figure 2 showed the variation of observed and estimated evaporation with time for five strategies selected for the study

The result obtained from this figure showed that, for strategy M- 3 which include wind speed, dry bulb and wet bulb temperature as the input parameters have least error and high $\mathrm{R}^{2}$ value as compared to other strategies. The MSE obtained for this strategy was 0.662 and the corresponding $\mathrm{R}^{2}$ value was 0.728 which showed that the observed evaporation of 
strategy M-3 was most accurate as compared to other observed values of evaporation. The MSE value was increased to 0.879 and the corresponding $\mathrm{R}^{2}$ value decreased to 0.684 for the strategy M-4 in which the input parameters considered were the dry bulb and wet bulb temperature.

This result showed that the wind speed along with the dry bulb temperature and wet bulb temperature has greater influence on the evaporation of the area. The highest $\mathrm{R}^{2}$ value indicated that the evaporation is mainly depend on the combination of independent variables such as wind speed, dry bulb and wet bulb temperature. The strategy M-1 has least $\mathrm{R}^{2}$ value and this includes all the five parameters as the input. Individually all the parameters has influence on the evaporation in different way.

But the combination of all the input has least influence as well as the combination with lesser parameters has good influence on the evaporation. The strategy M-5 has the highest MSE which was 1.424. This indicated that the observed evaporation corresponding to the combination of input variables of maximum temperature and minimum temperature has a high variation with the estimated evaporation through ANN technique. So this combination was least accurate for the evaporation modelling during pre-monsoon season. The obtained result is tabulated below.

\section{Monsoon season}

Monsoon meteorological data included monthly observations of parameters from June 2003 to September 2008, total 24 observations. The plot between observed and estimated evaporation are shown in figure 3 and the $\mathrm{R}^{2}$ value obtained from this figure indicated the correlation between estimated or observed evaporation.

Figure 4 showed the variation of observed and estimated evaporation with time for five strategies selected for the study respectively.

The strategy M-1 which includes all the parameters as input variables has least MSE and highest $\mathrm{R}^{2}$ value as compared to other strategies. It has the MSE value as 0.360 and has $\mathrm{R}^{2}$ value is 0.669 . In strategy M-3 which has the combination of wind speed, dry bulb temperature and wet bulb temperature as input parameters the MSE is increased to 0.363 as well as the strategy M-5 having maximum temperature and minimum temperature as the input variables have highest MSE of 0.720 which shows that the observed evaporation of strategy M-5 was least accurate as compared to other observed values of evaporation. In strategy M-5 the $\mathrm{R}^{2}$ value is decreased to 0.387 which showed that during monsoon season the maximum and minimum temperature has least significant role in the evaporation rate.

Table.1 The strategies selected for the study

\begin{tabular}{|l|l|l|l|l|l|}
\hline Input parameters & $\begin{array}{l}\text { Strategy } \\
\text { M- 1 }\end{array}$ & $\begin{array}{l}\text { Strategy } \\
\text { M-2 }\end{array}$ & $\begin{array}{l}\text { Strategy } \\
\text { M-3 }\end{array}$ & $\begin{array}{l}\text { Strategy } \\
\text { M-4 }\end{array}$ & $\begin{array}{l}\text { Strategy } \\
\text { M-5 }\end{array}$ \\
\hline Wind speed & $\checkmark$ & & $\checkmark$ & & \\
\hline Dry bulb Temperature & $\checkmark$ & $\checkmark$ & $\checkmark$ & $\checkmark$ & \\
\hline Wet bulb Temperature & $\checkmark$ & $\checkmark$ & $\checkmark$ & $\checkmark$ & \\
\hline Maximum Temperature & $\checkmark$ & $\checkmark$ & & & $\checkmark$ \\
\hline Minimum Temperature & $\checkmark$ & $\checkmark$ & & & $\checkmark$ \\
\hline
\end{tabular}


Table.2 MSE and R2 value obtained for pre-monsoon season

\begin{tabular}{|c|c|c|}
\hline Strategy & MSE & $\mathbf{R}^{2}$ value \\
\hline M- 1 & 1.364 & 0.507 \\
\hline M- 2 & 1.133 & 0.669 \\
\hline M- 3 & 0.662 & 0.728 \\
\hline M- 4 & 0.879 & 0.684 \\
\hline M- 5 & 1.424 & 0.509 \\
\hline
\end{tabular}

Table.3 MSE and R2 value obtained for monsoon season

\begin{tabular}{|c|c|c|}
\hline Strategy & MSE & $\mathbf{R}^{2}$ value \\
\hline M-1 & 0.360 & 0.669 \\
\hline M-2 & 0.507 & 0.562 \\
\hline M-3 & 0.363 & 0.648 \\
\hline M-4 & 0.415 & 0.606 \\
\hline M-5 & 0.720 & 0.387 \\
\hline
\end{tabular}

Table.4 MSE and R2 value obtained for post monsoon season

\begin{tabular}{|c|c|c|}
\hline Strategy & MSE & $\mathbf{R}^{2}$ value \\
\hline M-1 & 0.161 & 0.655 \\
\hline M-2 & 0.190 & 0.514 \\
\hline M-3 & 0.112 & 0.714 \\
\hline M-4 & 0.274 & 0.495 \\
\hline M-5 & 0.087 & 0.771 \\
\hline
\end{tabular}


Fig.1 Observed and estimated evaporation using ANN for corresponding strategies

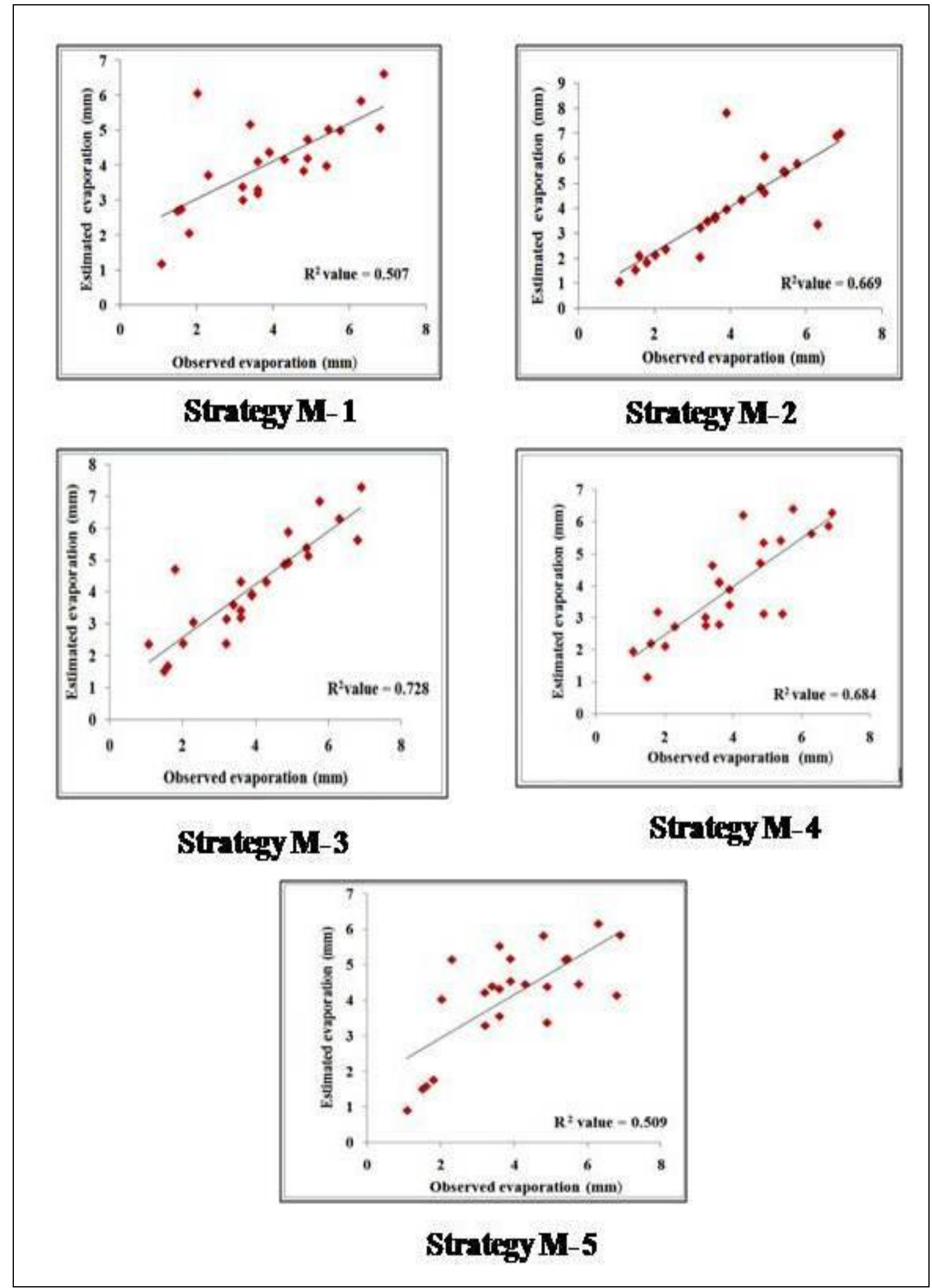


Fig.2 Variation between observed and estimated evaporation for corresponding strategies

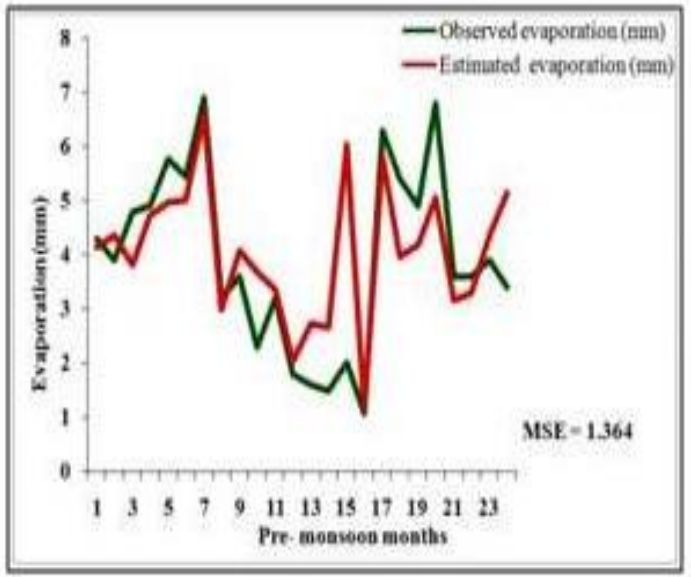

Strategy II-1

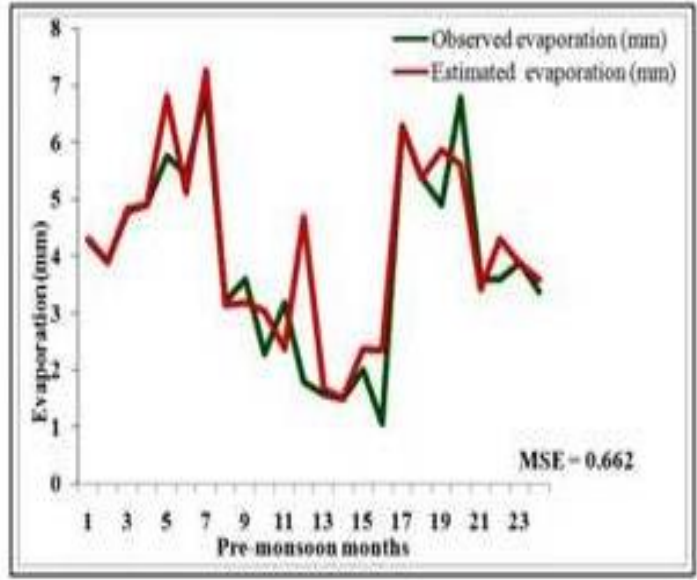

Strategy II-3

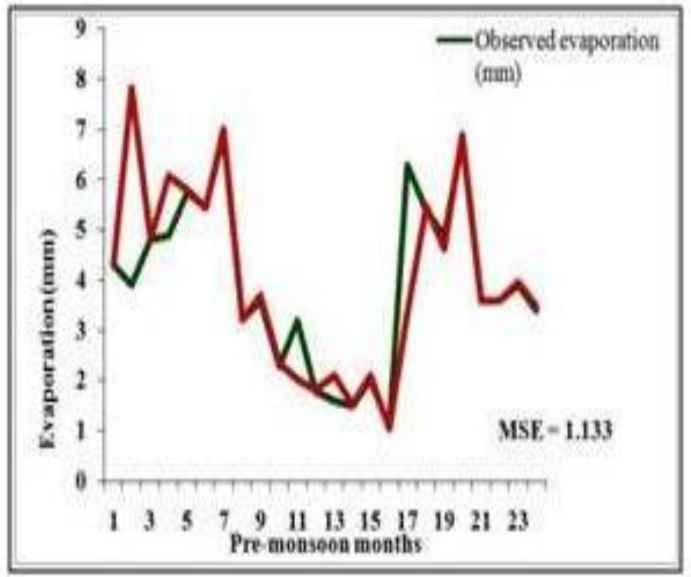

Strategy II-2

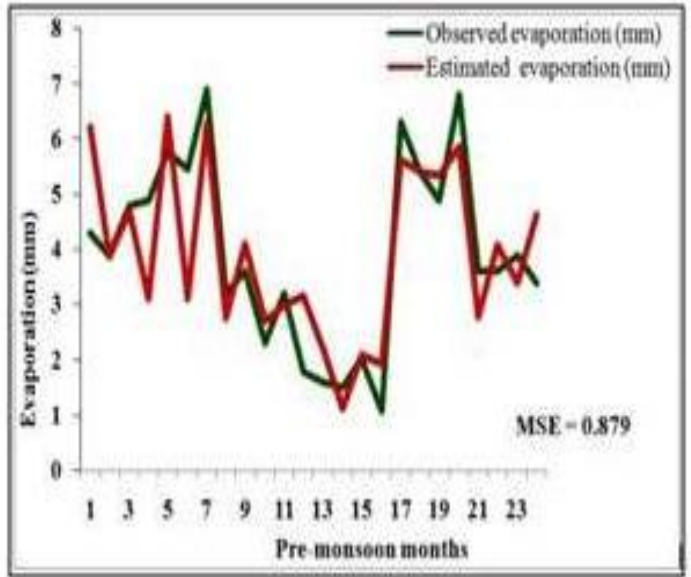

Strategy $14 \mathbf{4}$

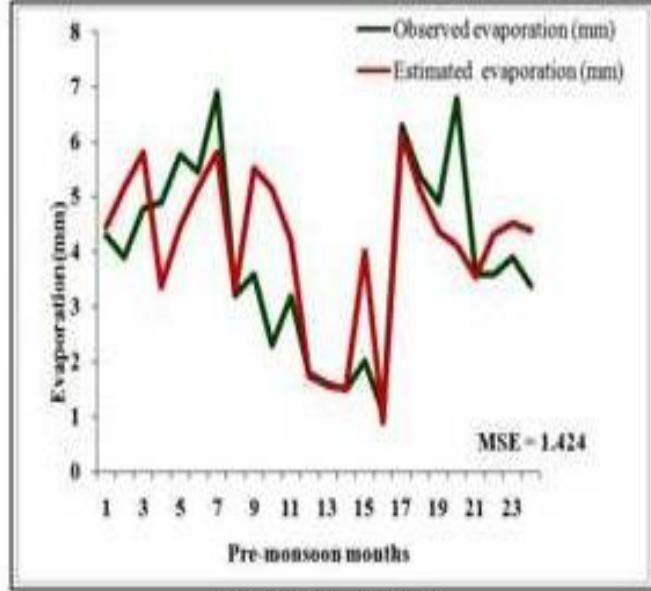

Strategy 145 
Fig.3 Observed and estimated evaporation using ANN for corresponding strategies

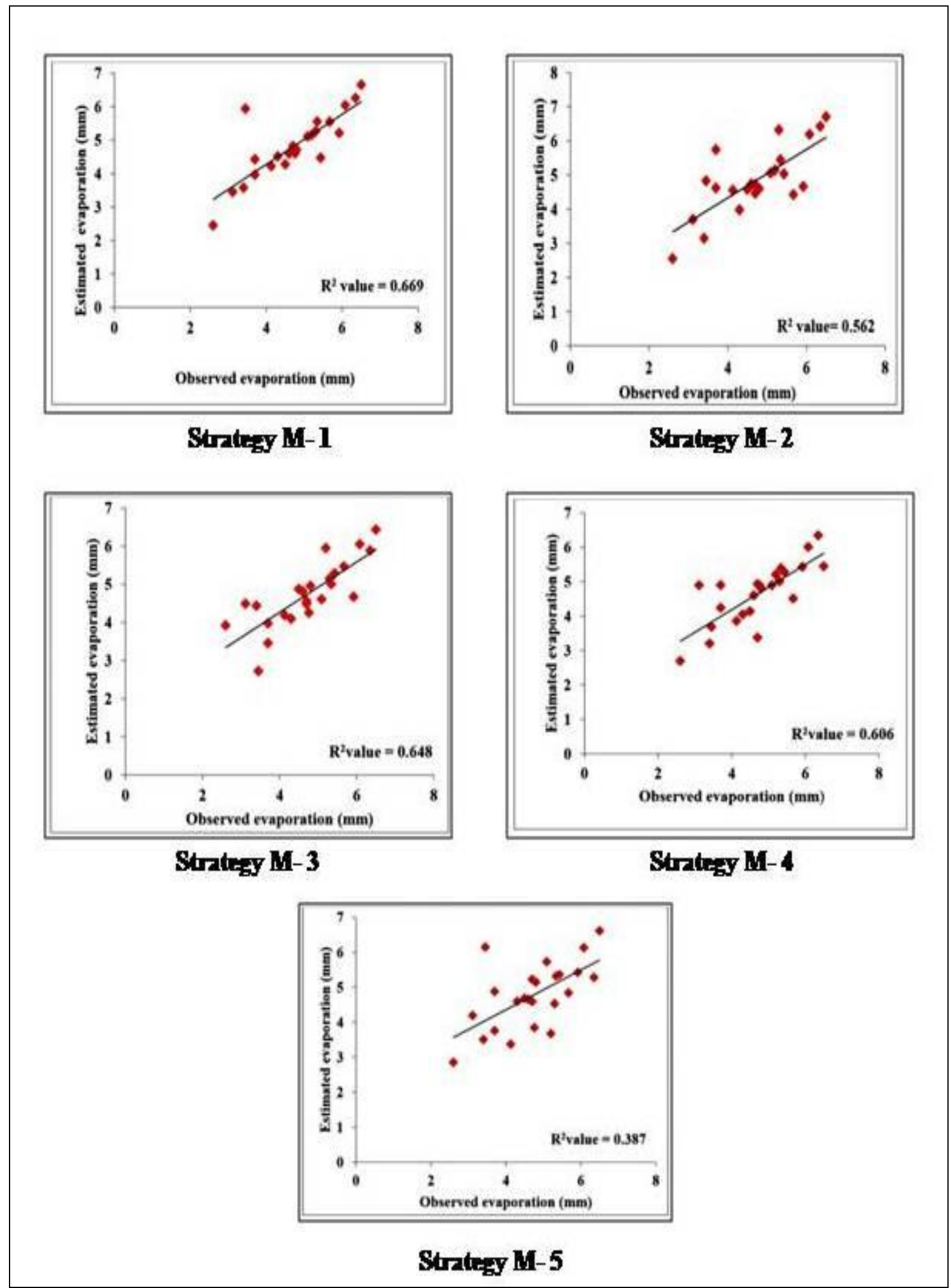


Fig.4 Variation between observed and estimated evaporation for corresponding strategies

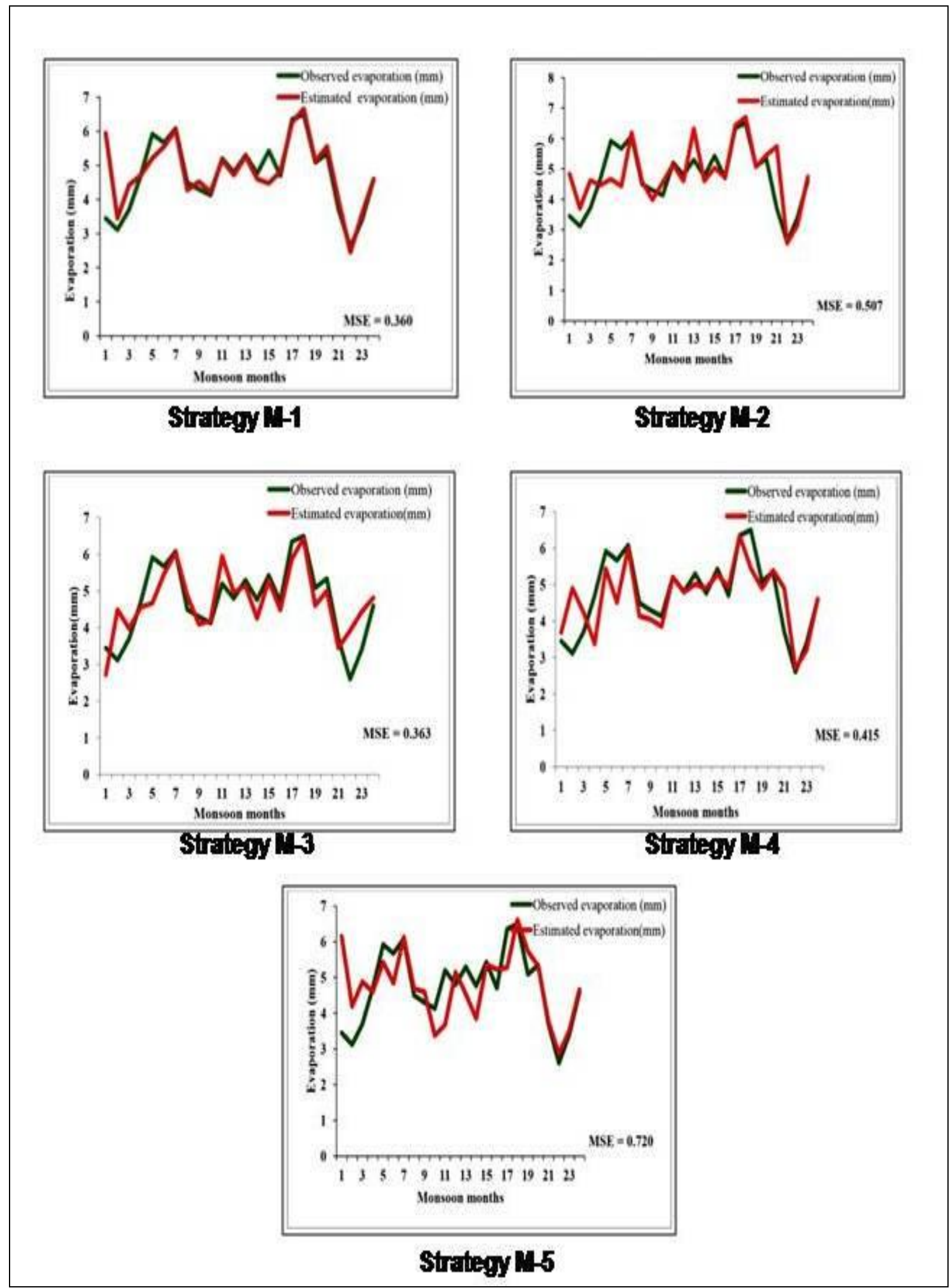


Fig.5 Observed and estimated evaporation using Artificial Neural Network for corresponding strategies

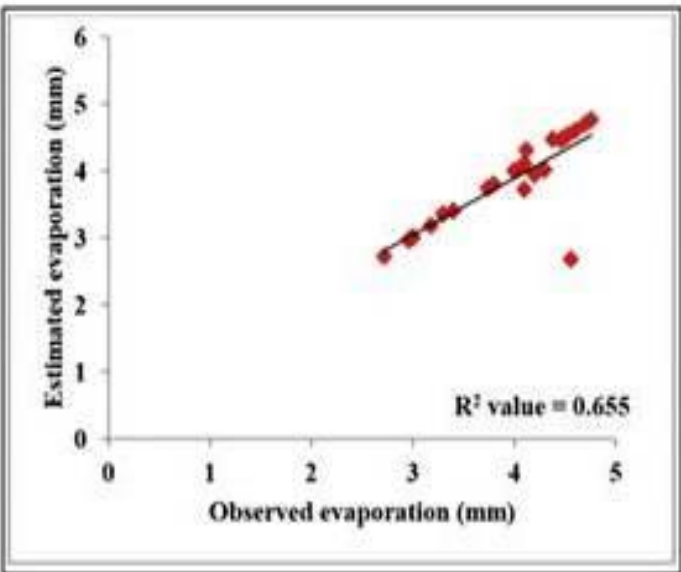

Strategy M-1

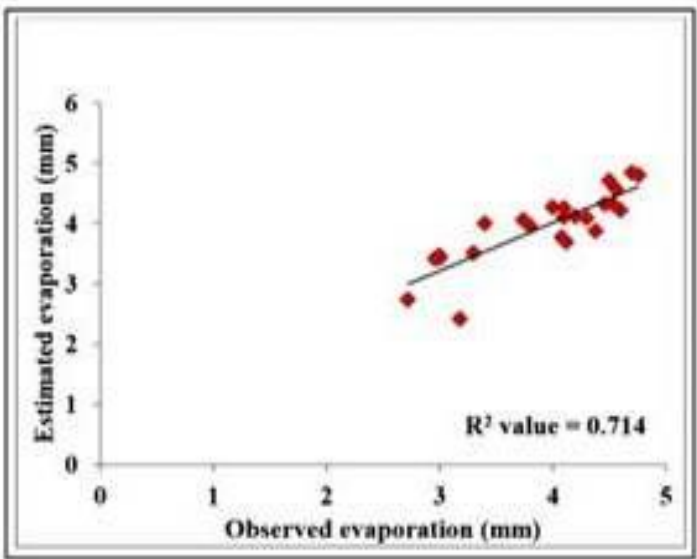

Strategy M-3

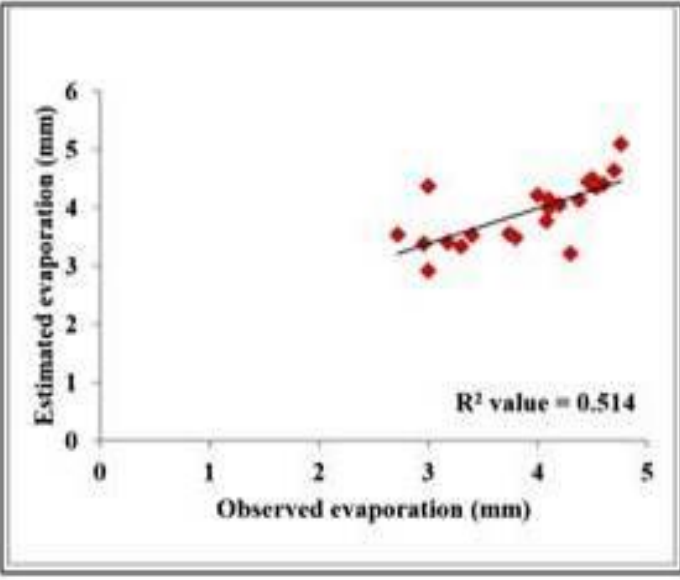

Strategy M-2

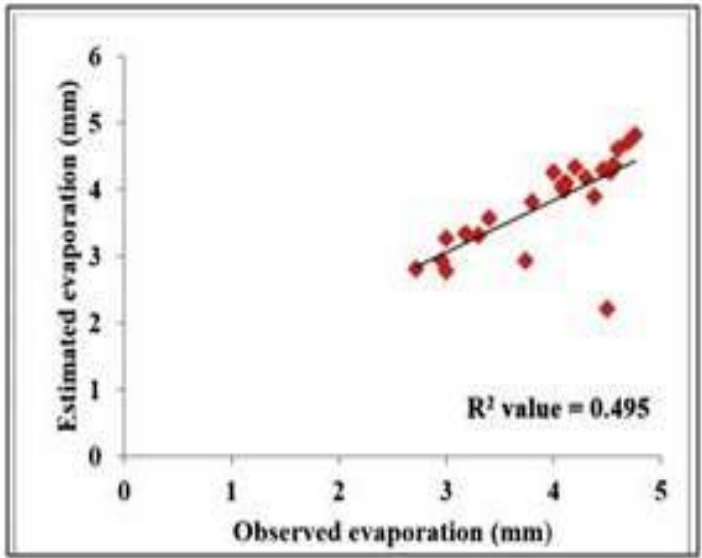

Strategy M-4

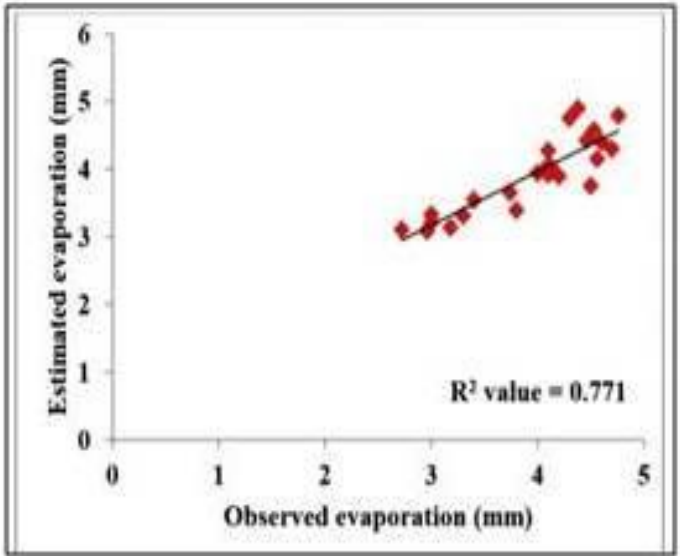

Strategy M-5 
Fig.6 Variation between observed and estimated evaporation for corresponding strategies

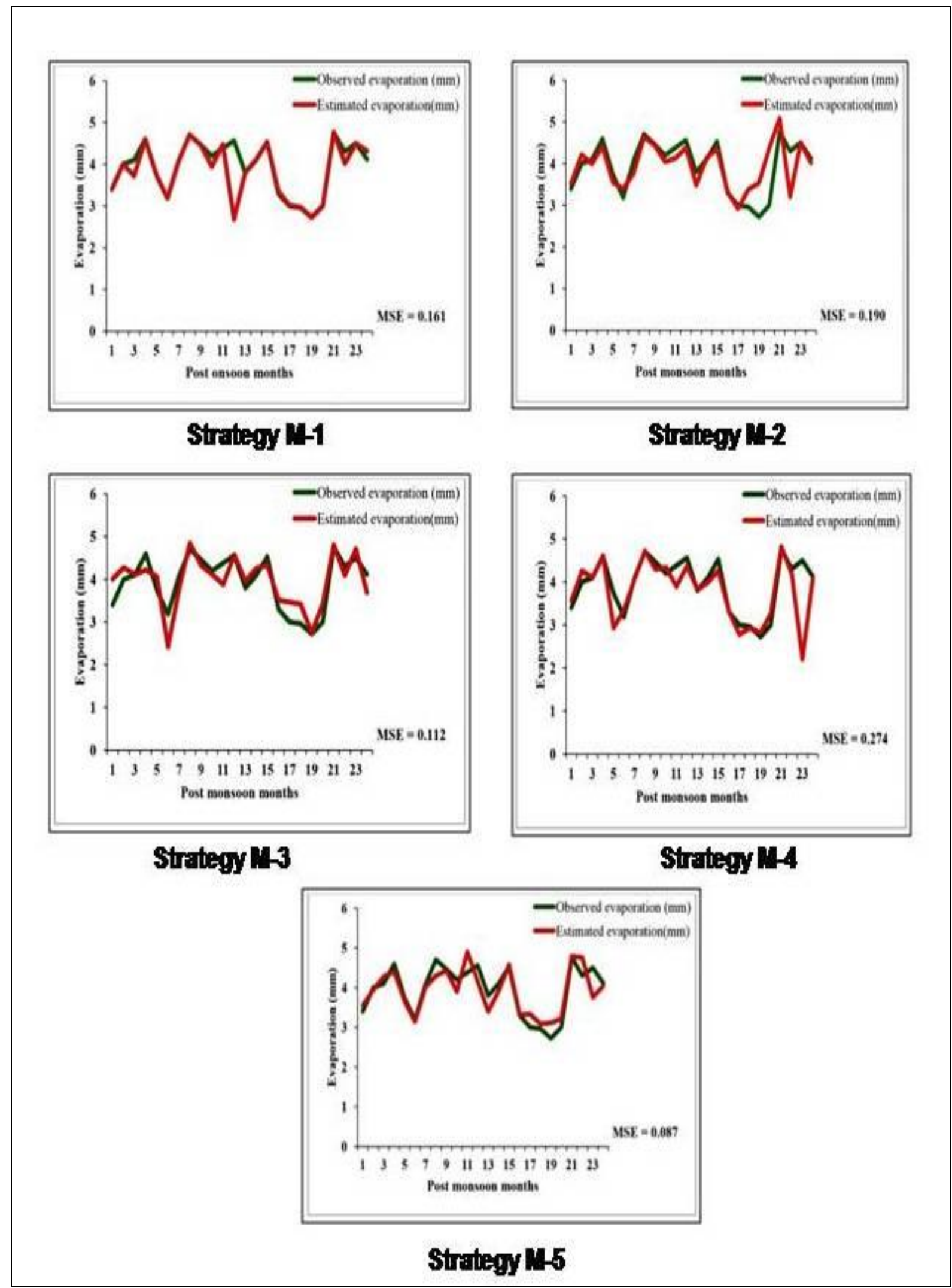


As in the case of pre-monsoon season, the evaporation rate is greatly influenced by the wind speed along with the dry bulb temperature and wet bulb temperature. Strategy M- 4 has MSE of 0.415 and $\mathrm{R}^{2}$ value of 0.606 , in which the dry bulb and wet bulb temperatures are the input variables. $\mathrm{R}^{2}$ value for the strategy M-3 which includes wind speed, dry bulb and wet bulb temperature as input parameters is 0.648 . From this it was clear that the best combination for estimating evaporation rate was strategy M- 3 and these parameters have greater influence on the evaporation rate during monsoon. The result obtained is tabulated below.

\section{Post monsoon season}

Post monsoon data consists of monthly observations of parameters from October 2003 to January 2009, total 24 observations. Five different combinations of input data were studied. The plot between observed and estimated evaporation are shown in figure 5 and the $R_{2}$ value obtained from this figure indicated the correlation between estimated or observed evaporation.

Figure 6 showed the variation of observed and estimated evaporation with time for five strategies selected for the study respectively. The strategy M-5 has least MSE value as well as the strategy M-4 has highest MSE value. Strategy M-5, the combination of minimum and maximum temperatures as the input variables has MSE value of 0.0869 as well as the strategy M-4, dry bulb and wet bulb as the input parameters, has MSE value of 0.273.

The result showed that the observed evaporation of strategy M-5 was most accurate as compared to other observed values of evaporation during post-monsoon season. The strategy M-5 has highest $R^{2}$ value as well as the strategy $\mathrm{M}-4$ has highest $\mathrm{R}^{2}$ value.
The $\mathrm{R}^{2}$ value of strategy $\mathrm{M}-5$ is 0.771 and it showed that the combination of maximum and minimum temperature has greater influence on the evaporation rate during post monsoon. The $\mathrm{R}^{2}$ value was reduced to 0.714 for the strategy M- 3 in which the wind speed, dry bulb temperature and wet bulb temperature was considered as the input variables. But in the case of M-4 strategy, in which the input variables considered were the dry bulb and wet bulb temperatures, has the $\mathrm{R}^{2}$ value of 0.495 only. From this result, it was clear that the wind speed along with the dry bulb temperature and wet bulb temperature has a significant role in the post monsoon evaporation rate. The results obtained are tabulated below.

From this study, it could be seen that the wind speed had greater influence on the evaporation rate during all seasons. During pre-monsoon season the combination of wind speed, dry bulb temperature and wet bulb temperature highly influenced the evaporation rate. The MSE and $\mathrm{R}^{2}$ value obtained for this combination is 0.662 and 0.728 respectively. During monsoon season the combination of all input variable (strategy M-1) highly influenced the evaporation rate with least MSE and $\mathrm{R}^{2}$ value and strategy M-3 with wind speed, dry bulb temperature and wet bulb temperature closely followed with MSE of 0.363 and $R^{2}$ value of 0.648 . In the premonsoon season the combination of wind speed, dry bulb temperature and wet bulb temperature (strategy M- 3) has greater influence on the evaporation rate.

During post monsoon season the combination of maximum and minimum temperature (strategy M-5) highly influenced on evaporation with least MSE and high $\mathrm{R}^{2}$ value of 0.087 and 0.771 respectively. The combination of the wind speed, dry bulb temperature and wet bulb temperature (strategy M-3) has also greater influence on 
evaporation with MSE value of 0.112 and $\mathrm{R}^{2}$ value of 0.714 . This inferred that during post monsoon season the wind speed along with the dry bulb temperature and wet bulb temperature has greater influence on the evaporation rate. Out of the five strategies considered for the study, the strategy with wind speed, dry bulb temperature and wet bulb temperature (strategy M- 3) was found to be the accurate combination for the estimation of evaporation during all the seasons with comparatively least MSE and high $\mathrm{R}^{2}$ value when compared with other strategies. Hence, it can be concluded that the combination of wind speed, dry bulb temperature and wet bulb temperature has great influence on the evaporation during all seasons.

\section{References}

Bruton, J. M., McClendon, R. W. and Hoogenboom, G. 2000. Estimating daily pan evaporation with artificial neural networks. Trans. ASAE. 43 (2): 491-496.

Chetan, M., and Sudheer, K. P. 2006. A hybrid linear- neural model for river flow forecasting. Water Resour. Res. 42.

Dawson, C. W., and Wilby, R. 1998. An aritificial neural network approach to rainfall- runoff modelling. Hydrol. Sci. J. 43(1): 47-66.

Eslamian, S. S., Gohari, S. A., Biabanaki, M. and Malekian, R. 2008. Estimation of monthly pan evaporation using artificial neural networks and support vector machines. J. of appl. sci. 8(19): 34973502 .

Jain, A., Sudheer, K. P. and Sreenivasalu, S. 2004. Identification of physical processes inherent in artificial neural network rainfall runoff models. Hydrol. Processes. 18: 571-581.

Kaltech, A. M., 2008. Rainfall-runoff modelling using artificial neural networks (ANNs): modelling and understanding. Capsian J. Eny. Sci. 6(1): 53-58.

Kaltech, A. M., 2013. Monthly River flow forecasting using artificial neural network and support vector regression models coupled with wavelet transform. Computers\& Geosciences Elsevier. 54: 1-8.

Keskin, M. E., and Terzi, O. 2006. Artificial neural network models of daily pan evaporation. J. Hydrol. Engng. 11(1): 65-70.

Kim, S., and Kim, H. S. 2008. Neural networks and genetic algorithm approach for nonlinear evaporation and evapotranspiration modeling. $J$. of Hydrol. 351: 299-317.

Kisi, O., 2006. Daily pan evaporation modelling using a neuro-fuzzy computing technique. J. of Hydrol. 329: 636-646.

Landeras, G., Barredo, A. O. and Lopez, J. J. 2009. Forecasting weekly Evapotranspiration with ARIMA and Artificial Neural Network models. $J$. irrig. Drain. Engng. 135(3): 323-334.

Moghaddamnia, A., Gousheh, M. G., Piri, J. and Han, D. 2009. Evaporation estimation using artificial neural networks and adaptive neuro-fuzzy inference system technique. Advances in water Resour. 32: 88-97.

Molina Martinez, J. M., Alvarezv, M., Gonzalez Real, M. M. and Baille, A. 2006. A simulation model for predicting hourly pan evaporation from meteorological data. J. of Hydrol. 318(1-4): 250-261.

Ozgur Kisi, 2009. Daily pan evaporation modelling using multi-layer perceptrons and radial basis neural networks. Hydrological Processes. 23(2): 213223.

Ozlem, T., and E volkesk, M. 2005. Modeling of daily pan evaporation. J. of Appl. Sci. 
5(2): 368-372.

Pankaj Kumar., \& Devendra Kumar. 2013. Evaporation modelling using weather data. J. of Soil and Water Conserv. 12(3): 234-239.

Piri, J., Amin, S., Moghaddamnia, A., Keshavarz, A., Han, D., and Remesan, R. 2009. Daily Pan Evaporation Modeling in a Hot and Dry Climate. $J$. Hydrol. Engng. 14(8): 803-811.

Shamseldin, A. Y., 1997. Application of a neural-network technique to rainfallrunoff modelling. J. Hydrolol. Amsterdam. 199: 272-294.
Shirgure, P. S., and Rajput, G.S. 2014. Modeling daily pan evaporation using artificial neural networks. Indian J. of soil conserv. 42(2): 119-129.

Sudheer, K. P., Gosain, A. K., Mohana, R. D. and Saheb, S. M. 2002. Modeling evaporation using an artificial neural network algorithm. Hydrol. Processes. 16: 3189-3202.

Taher, S. A., 2003. Estimation of potential evaporation: Artificial Neural Networks versus conventional methods. J. King saud univ. 17(1): 1-14.

\section{How to cite this article:}

Sajeena, S., V. Amrutha Gayathry and Sharmina, V.K. 2017. Estimation of Pan Evaporation Using Artificial Neural Networks - A Case Study. Int.J.Curr.Microbiol.App.Sci. 6(9): 30523065. doi: https://doi.org/10.20546/ijcmas.2017.609.376 